\title{
VIOLÃO E IDENTIDADE NACIONAL: A “MORAL” DO INSTRUMENTO
}

\author{
ACOUSTIC CUITAR AND NATIONAL IDENTITY: THE \\ "MORAL" OF THE INSTRUMENT
}

\author{
Carlos Fernando Elias Llanos \\ Universidade de São Paulo \\ fllanos@usp.br
}

\section{Resumo}

O texto analisa parte da literatura sobre a história do violão no Brasil nas primeiras décadas do século XX, no contexto das complexas relações sociais e políticas da Primeira República na cidade de Rio de Janeiro. A ideia central é discutir a noção de violão-arte, que teria surgido a partir da tradição do violão erudito europeu (como construção de discurso), em contraposição a outras práticas violonísticas que a historiografia do instrumento não menciona ou o faz ressaltando sua progressiva aceitação "moral" e distanciamento do estigma da boêmia e a vadiagem. $O$ texto conclui problematizando como o violão configurou-se como meio de execução e corporificação de representações sociais, que chamamos de instrumento-documento ${ }^{1}$, violentamente empobrecido (pois, na passagem do século XIX ao XX ele era sinônimo de marginalidade), precariamente empregado, com escassa ou nula instrução formal (não havia onde aprender a tocar) e principalmente autodidata (aprendido na prática e na tradição oral).

Palavras-chave: Violão; Musicologia; Discurso; Identidade.

I $\bigcirc$ termo foi criado com o intuito de evidenciar a dependência simbólica entre o violão e seu executante, dependência que afeta e ressignifica a ambos arbitrariamente e vive permeada de contextos complexos (sociais, culturais, políticos). Também, pretendo deslocar a atenção ao papel do violão como veículo e agente material e simbólico. Nas páginas seguintes explicarei com mais detalhe este e outros conceitos teóricos. 


\begin{abstract}
The text analyzes part of the literature on the history of the guitar in Brazil, during the first decades of the twentieth century, in the context of complex social and political relations of the First Republic in the city of Rio de Janeiro. The central idea is to discuss the notion of guitar-art that would have arisen from the tradition of European classical guitar (as a discourse construction), as opposed to other guitar practices not mentioned in instrument's historiography or, when it does, is by highlighting its gradual "moral" acceptance and distance of stigma of bohemian and vagrancy. The text concludes questioning how the guitar set up as a means of implementation and embodiment of social representations, we call instrument-document, violently depleted (because, in the late nineteenth to the twentieth century it was synonymous with marginality), precariously employed, with little or no formal education (there was nowhere to learn to play) and mainly self-taught (learned in practice and oral tradition).
\end{abstract}

Keywords: Guitar; Musicolog; Discourse; Identity.

\title{
Lista de figuras
}

Figura 1 - Aviso de aulas de violão no jornal Correio da Manhã, Rio de Janeiro, ano 1, n 148, pp. 4, col. Annuncios, sábado, 09 de novembro de 1901. Dominio público. Referência: Fundação Biblioteca Nacional - BNDigital.

Figura 2 - PEDERNEIRAS, Raul. Scenas da vida carioca: caricaturas de Raul. vol. 1. Rio de Janeiro: Officinas Graphicas do Jornal do Brasil, 1924, p. 31 . Dominio Público. 


\section{Introdução}

Existem esforços por entender os processos complexos da construção da identidade brasileira desde o futebol' ${ }^{2}$ o samba ${ }^{3}$, os estudos de etnicidade 4 , a mídia ${ }^{5}$ a comida6, por citar só alguns.

No presente trabalho, um ponto de partida foi a época em que o Rio de Janeiro era o principal centro urbano, econômico e político do país. A sua peculiar efervescência cultural e seu papel na configuração de uma identidade brasileira ${ }^{7}$, na passagem do século XIX ao XX' ram desta cidade um palco excepcional para compreender como iam sendo construídas as brasilidades no violão:

instrumento chegou ao Rio de Janeiro num momento bastante peculiar na história da cidade. Não foram poucas e tampouco menos profundas as transformações econômicas e sociais vivenciadas pelos cariocas com a chegada da familia imperial. A experiência de urbanização avassalou os diversos setores da sociedade, com marcadas transformações na paisagem, nas relações sociais, no cotidiano dos habitantes. [...] $\bigcirc$ violão espalhase pela cidade na medida em que no ambiente urbano se

2 Cf: DAMATTA, Roberto et alli. (1982), Universo do Futebol: esporte e sociedade brasileira. Rio de Janeiro: Pinalotheke.

3 Cf.: VIANNA, Hermano. O mistério do samba. 4ed. Rio de Janeiro: Jorge Zahar Ed.; Ed. UFRJ, 2002; SANDRONI, Carlos. Feitiço decente: transformações do samba no Rio de Janeiro, 1917-1933. Rio de Janeiro: Jorge Zahar Ed, 2012

4 Cf.: SCHUARCZ, Lilia Moritz. O Espetáculo das Raças: cientistas, instituicões e questão racial no. Brasil, 1870-1930. São Paulo: Cia. das Letras, 1995; MUNANCA, Kabengele. Rediscutindo a mestiçagem no Brasil: identidade nacional versus identidade negra. São Paulo: Editora Vozes, 1999

5 Cf:: SODRÉ, Muniz. Claros e escuros: identidade, povo e mídia no Brasil. São Paulo: Editora Vozes, 1999

6 Cf: MACIEL, Maria Eunice. Uma cozinha à brasileira. Revista Estudos Históricos, vol. I, no 33. Rio de Janeiro: FCV, 2004, pp. 25-39

7 Sobre esta particularidade, temos que "a abertura dos portos brasileiros ao comércio exterior promoveu um grande fluxo de comerciantes e viajantes estrangeiros para o país, e vários deles deixaram descrições muito interessantes a respeito da vida e dos costumes do Brasil durante o século XIX. Boa parte desses relatos diz respeito ao Rio de Janeiro, onde a família real vivia. Exatamente por isso o Rio se tornou uma cidade "cosmopolita", em que as pessoas mais abastadas tentavam se comportar de uma maneira que elas supunham ser a europeia. Lá, mais fortemente, a difusão cultural do gênero de vida burguês, eminentemente urbano, começou a se desenvolver entre as elites". (OLIVEN, 2002, pp. 18) 8 Rio de Janeiro também teve um papel privilegiado na linha de pesquisa dedicada ao estudo das cidades no Brasil. Cf.: PECHMAN, Robert Moses. Cidades estreitamente vigiadas: o detetive e o urbanista. 1999, 427f, Tese (Doutorado em História). Instituto de Filosofia e Ciências Humanas, Universidade Estadual de Campinas. Campinas.

\section{9}


organiza e se difunde o conjunto de choro. Através dele depura-se o processo de tradução ${ }^{9}$ do repertório europeu para uma possivel linguagem nacional. Inicialmente moldura instrumental amalgamada às formas de origem, a elas imprime caráter próprio, dando vazão ao surgimento do que se pode chamar "linguagem do choro", articulação musical que transcende especificações de forma, de vestimenta e de conteúdo. Nenhum outro instrumento suscitou tantos comentários e críticas quanto o violão. Pau e corda que acalentou modinhas, embalou lundus e se fez tamborim para marcar e difundir o samba nascente. Instrumento de capadócio, capoeira, boêmios e malandros. Nessa maldição, a contrapartida simbólica: o atestado de timbre instrumental mais tipicamente brasileiro. $\bigcirc$ violão deu sempre o que falar. Nas críticas de jornais, nos concertos, na literatura. Envolveu a paixão dos que o defenderam, atraindo a mesma paixão daqueles que o atacaram (TABORDA, 2011 , cap. 4).

$\bigcirc$ violão aqui possui uma dupla condição que denominarei de instrumento-documento ${ }^{10}$, pois assim desejo afirmar que é o elemento articulador de uma série de significados sociais a partir de sua existência física (enquanto objeto), e não é só depositário passivo de paixões que o defendem ou atacam, mas, como toda cultura material, constituísse num artefato ativo construído de modo a transformar materialmente, socialmente e ideologicamente (HODDER, 1998, pp. 114).

Também o violão é instrumento-documento, porque serve a uma linguagem específica (no caso, o choro) que faz dele um retrato, um ato de fé, testemunha, atestado e comprovante da idiossincrasia brasileira da época. Além disso, o violão acompanhou o processo de urbanização e o desenvolvimento da sociedade industrial, que produz problemas novos:

9 termo tradução é contestável na medida em que o choro não necessariamente acabou sendo uma releitura do repertório europeu strictu sensu. Acredito que o sentido aqui é o de construção de uma linguagem musical.

$10 \bigcirc$ termo foi criado com o intuito de evidenciar a dependência simbólica entre o violão e seu executante, dependência que afeta e ressignifica a ambos arbitrariamente e vive permeada de contextos complexos (sociais, culturais, políticos). Também, pretendo deslocar a atenção ao papel do violão como veículo e agente material e simbólico. Nas páginas seguintes explicarei com mais detalhe este e outros conceitos teóricos.

\section{0}


O violão esteve presente na sociedade brasileira, tanto nos círculos da elite quanto nas manifestações das camadas mais populares. Assumiu lugar único, enquanto meio de execução e corporificação de representações sociais, constituindo-se num ponto de partida privilegiado para investigar a particular dinâmica assumida pela cultura musical no Rio de Janeiro de fins do século XIX às primeiras décadas do século XX. (TABORDA, cap. 4 - grifo nosso).

Tal "incapacidade artística" do violão (CASTAGNA, ANTUNES, 1994, pp. 3) sentou as suas origens na soma de diversos fatores, entre eles: o "processo de reeuropeização marcado primordialmente pela franca subversão dos hábitos lusos" (TABORDA, 201 l, cap 4), seu estigma como instrumento associado à vadiagem e à boemia (CLOEDEN, PEREIRA, 2012, pp. 72) e arquetípico das seresteiras "orquestras de pobre", mais tarde batizadas de "regionais" pelas rádios (BARTOLONI, 2000, pp. 76-79) e no amadorismo com que se aprendia e executava, pois, "à época, não havia no Brasil a categoria do artista virtuose, capaz de realizar façanhas e de se especializar num único instrumento" (TABORDA, 2011 , cap. 2).

Por isso, este mesmo meio de execução e corporificação de representaçöes sociais se configura como um instrumento-documento violentamente empobrecido (pois, na passagem do século XIX ao XX ele era sinônimo de marginalidade), precariamente empregado (ninguém vivia da música e muito menos tocando violão), com escassa ou nula instrução formal (não havia onde aprender a tocar) e principalmente autodidata (aprendido na prática e na tradição oral). Estas condições teriam dificultado sua mobilidade social e, consequentemente, o da parcela da população que ele representava.

No trecho a seguir, preste atenção aos referentes étnicos, à descrição das condições materiais, da vestimenta, às referências geográficas dos bairros, aos adjetivos:

[...] rapazelhos de calças abombachadas, grandes cabeleiras, lenço no pescoço e chapéu desabado, pardavascos, negros-crioulos, brancos [...] toda uma freguesia 
perguntona, espalhafatosa, vozeiruda, que arranca notas de dois e cinco mil-réis do fundo de lenços de chita, muito sujos, armados em carteiras, para comprar as brochurinhas, postas em capas de espavento, não raro aos empurrões, aos gritos, o violão debaixo do braço, ou experimentando flautas, oboés, cavaquinhos... É o Chico Chaleira do morro do Pinto, é o Trinca-Espinhas da Travessa da Saudade, no Mangue, o Chora-na-Macumba, o Janjão da Polaca, o Espanta-Coió, toda uma legião de cantores, de seresteiros, de serenateiros, a flor da vagabundagem carioca, essência, sumo, nata da ralé" (EDMUNDO, 2003, pp. 454).

Mas, podemos falar de um violão brasileiro ainda nessa época? Diversos autores coincidem em afirmar que o violão pode ser considerado como "arte" entre os anos de 1916 e 1917 (CASTACNA, ANTUNES, 1994; CASTACNA, SCHWARZ, 1993; TABORDA, 2011, pp. 87-96; CLOEDEN, PEREIRA, 2012; BARTOLONI, 2000, pp. 57-59).

Tudo aquilo que não se enquadrava dentro da definição de violão-arte, a tradição violonística "às avessas", poder-se-ia entender como um tipo peculiar de história dos vencidos ${ }^{11}$ do violão brasileiro, daqueles que acumularam experiências político-poéticas que, de um lado, devieram na inserção do instrumento como uma prática comum no convívio social e, por outro lado, construíram uma "outra performance brasileira" do instrumento.

É claro que ao inferir desta forma estou escolhendo deliberadamente apenas um lado da história, pois, embora o violão sofresse certo preconceito para a elite da época, resulta quase impossivel acreditar que a própria não tenha tido ciência e, de fato, conhecimento do instrumento ${ }^{12}$. Desejo chamar a atenção ao fato de que o violão era um instrumento que não compartilhava, na época, da moral do violino e do piano, considerados nobres ${ }^{13}$. Seja modinha ou fado, o violão e

II O termo alude ao livro de Nathan Wachtel, Los vencidos: los indios del Perú frente a la conquista española (1530-1570). Trad. de Antonio Escohotado. Madrid: Alianza Editorial, 1976.

12 Pois existiam métodos para aprender a tocar violão sem auxilio de professor e sem conhecimento de música, como veremos nas páginas seguintes.

13 Como bem confirma o comentário do Jornal do Commercio de 25 de julho de 1916 , em referência à apresentação do violonista paraguaio Agustín Barrios no país: "Que o violão tenha um repertório limiładíssimo não admira, porque, com exceção do piano e do órgão, isso acontece a todos os instrumentos, até mesmo ao violino, cujos foros de nobreza ninguém contesta" (Apud BARTOLONI, 2000, pp. 58). 
a guitarra portuguesa padeciam, até bem entrada a primeira década do século XX, o estigma de serem meros instrumentos "em cujas cordas palpitam tristezas, lágrimas e risos de dois povos intimamente ligados pela afinidade de raça, de coração e de língua"14 e, não obstante thes era negado o Parnaso reservado a outros instrumentos "mais altos"15. Em todo caso, também poder-se-ia inferir a existência de uma tensão -insisto- moral, da performance pública do instrumento?:

- reconhecimento do violão como instrumento popular por excelência, não apenas pelo desempenho enquanto suporte harmônico dos gêneros da música típica, mas pela associação às camadas desfavorecidas da sociedade, foi o mote para sustentação do discurso erigido a partir de princípios do século XX, no qual, uma vez que essencialmente popular ${ }^{16}$, o violão deveria ser banido dos círculos onde a verdadeira arte seria praticada. (TABORDA, 2011 , pp. 196).

No entanto, o mesmo violão desdenhado reaparecia aliviado de seu estigma nas mãos de intermediários culturais que, literalmente, the "lavavam a alma", como no caso dos anúncios de jornal (Fig. I) que ofertavam aulas do instrumento ${ }^{17}$, cuja escrita parece transparecer a intenção de não querer ser confundido com seus desordeiros pares.

\footnotetext{
14 Audição de guitarra. Jornal do Commercio, Rio de Janeiro, ano 90, n.147, p.6, col. Theatros e Musica, sábado, 27 mai. 1916. (Apud CASTACNA, ANTUNES, 1994, pp. 2)

15 Curiosa a forma como o texto apresenta uma noção de "povo" descrita de forma tão visceral (raça, coração, língua) e associada a determinados humores ou estados de ânimo (tristeza, lágrima, riso). Acredito que o violão e a guitarra portuguesa aparecem inseridos assim numa visão neoplatônica do corpo e alma opostos entre si, pela qual, aos primeiros caberia uma existência mortal, maculada, diferente da alegada espiritualidade de instrumentos como o violino e o piano. Cf.: MARCONDES, Danilo; JAPIASSÚ, Hilton. Neoplatonismo. In: Dicionário básico de filosofia. Rio de Janeiro: Jorge Zahar, 1996. pp. 200.

16 Argumento que será melhor contextualizado nas páginas seguintes, pois essa relação foi bem mais complexa e demonstrou ter muitas conexões comuns, pelo qual não pode simplesmente ser reduzida apenas a uma rejeição do violão enquanto popular.

17 Não é o objetivo principal desta pesquisa fazer um levantamento minucioso deste tipo de publicações. Elas serão utilizadas na medida em que ajudem a entender o problema central: a construção das brasilidades no violão. Contudo, vale mencionar que o instrumento já aparecia em anúncios do Almanak Administrativo, Mercantil e Industrial do Rio de Janeiro (conhecido também como Almanak Laemmert), desde 1847. Cf. TABORDA, 2011, cáp. 2
}

\section{3}




\section{Professor de Violão}

Lecciona-se este mavioso instru. mento, por mnsica e sem musica, por methodo facil e rapids, garantindo a seus discipulos fazerem progressos em poucas lições, preços modicos. Acceita recados para leccionar em casa de familias; por especial obsequio no estabelecimento de pianos e i musicas dos srs. Buschmann, Guimarães \& Irmão. Rua dos Ourives n. 50. Tambem lecciona na rua da Carioca n. $1 \mathrm{~N}$.

Fig. I. Aviso de aulas de violão. Jornal Correio da Manhã, Rio de Janeiro, ano I, n 1 48, pp. 4, col. Annuncios, sábado, 09 de novembro de $1901 .{ }^{18}$

Podemos pensar numa comunidade formada por autodidatas, amadores e instrumentistas experientes (enquanto professores, não concertistas strictu sensu) como sendo um recorte das brasilidades violonisticas da época e parte de um legado empírico do violão brasileiro repleto de figuras das quais se tem pouca informação' ${ }^{19}$. Imagino até como se o instrumento tivesse uma "vida pública" e uma "vida privada": a de um "violão-arte" que almeja se alinhar aos postulados de um ensino

18 Conteúdo extraido do site da biblioteca digital da Fundação Biblioteca Nacional BNDigital. Disponivel em <http://memoria.bn.br/pdf/089842/per089842_1901_00148.pdf> Acessado em 17 de maio de 2016.

19 Moraes ensaia uma explicação proveniente da área da História, que chama à reflexão: "No Brasil, a situação das pesquisas em torno da música de maneira geral e a popular de modo especial é bastante desigual e repleta de paradoxos. De um lado a bibliografia reproduziu há até poucos anos de modo evidente esse quadro genérico, seguindo a linha descritiva do fato musical ou baseando-se exclusivamente na biografia do autor, $e$, às vezes, promoveu uma interseção conservadora das duas interpretações" (ldem, 2000, pp. 207 - grifos nossos). Fora da academia, há exemplos sem os quais muitos da referida comunidade formada por autodidatas, amadores e instrumentistas experientes permaneceriam desconhecidos. Cf.: PINTO, Alexandre Gonçalves. $\bigcirc$ choro: reminiscencias dos chorôes antigos. [Rio de Janeiro]: Typ. Clória, 1936. $210 p$. Em relação a esta publicação, recomendo a análise feita por Pedro de Moura Aragão, "O carteiro e a cultura popular na Bélle Époque: Alexandre Gonçalves Pinto e o Choro". In: Anais do SIMPOM, v. 2, п. 2, 2012, pp. 878-886. 
musical europeu de séc. XIX, avesso ao "violão-povo", sempre vigiado pela missão moralista das belas artes. Parte do discurso pronunciado por ocasião da instalação do Conservatório de Música carrega este pensamento, que se estendeu até bem entrado o século XX:

Por todas estas considerações de palpitante interesse, e por ser a cultura da música útil, moral, e necessária, é que as Nações mais ilustradas do século em que vivemos têmse esmerado em estabelecer Conservatórios, tendentes a propagar e conservar a arte em toda a sua pureza, cônscia de que as instituições humanas devem ter por base a moralidade, e que as Belas-Artes são essencialmente morais, porque tornam o indivíduo que as cultiva mais feliz e melhor cidadão. (SILVA20 apud AUCUSTO, 2008, pp. 56-57)

\section{"O violão brasileiro já é uma arte".}

Pesquisas musicológicas coincidem em informar quatro momentos marcantes na afirmação do violão no país e, consequentemente, na construção da sua identidade. $O$ primeiro é o ano de 1908, que destaca a importância do poeta e músico Catulo da Paixão Cearense $(1863-1946)^{21}$ :

O sucesso de Catulo abriu-lhe portas, a ele e ao violão, que de instrumento de boêmios virou instrumento nobre. Em 1908, o violão, pelas mãos e dedos de Catulo, entrou no Instituto Nacional de Música. $\bigcirc$ Catulo, poeta e violonista, foi convidado por Nair ${ }^{22}$ para os saraus do Palácio. E desde o começo encantou a todos com a sua simplicidade e maestria no verso e no violão (RODRICUES, 2002, pp. 75).

20 SILVA, Francisco Manuel. Discurso pronunciado por ocasião da instalação do Conservatório de Música. Rio de Janeiro, 1848. Documento manuscrito. Biblioteca Nacional. Seção de Manuscrito: II, 34,26,42.

21 Sobre a importância de Catulo, cf.: CASTACNA, ANTUNES, 1994, pp. 2; e MARCONDES, 1998, p. 190.

22 Nair de Teffé, esposa do então presidente (1910-1914) Marechal Hermes da Fonseca.

\section{5}



simbólica:

próprio Catulo também relataria sua "façanha", embora

Em 5 de julho de 1908, dei uma audição de modinhas e violão no Instituto Nacional de Música, de que era diretor - maestro Alberto Nepomuceno. Foi uma das maiores enchentes daquela casa. Fiz, como já disse o grande Hermes Fontes, uma grande reforma na modinha, civilizando-a. Está ganha a primeira batalha. Penetramos na fortaleza dos clássicos... Mas ainda falta alguma coisa. (MAUL, 1971, pp. 67 apud TABORDA, 2011 , pp. 190 - grifo nosso).

O esforço de Catulo na época apenas deixou registrado um desejo de espaço social para um "violão-arte" moralizado pela chancela do Instituto Nacional de Música, com a qual buscava não se fazer confundir com o "violão-povo", daí que buscasse "apresentar-se, e a seu grupo de músicos, como gente 'honesta,' 'funcionários públicos', 'devidamente trajados', 'diplomados pelo Instituto Nacional de Música' etc" (FERLIM, 2011, pp. 190).

Do fato é possivel deduzir que o instrumento tinha uma carga moral bastante negativa mesmo para aqueles que o praticavam nos moldes dos métodos europeus que já circulavam no Rio de Janeiro ${ }^{23}$ e posteriormente se produziriam no país ${ }^{24}$. A história do violão na sociedade brasileira era, pois, vivida por todos, independentemente da classe social. $\bigcirc$ que mudava era o grau e ciência do preconceito que isto significava, assim como as formas de lidar com ela.

23 “O músico francês Pierre Laforge, que por volta de 1834 estabeleceu negócio no Rio de Janeiro dedicando-se a impressão regular de peças musicais, foi o responsável pela introdução na sociedade carioca do primeiro método de viola francesa, já por esta época denominada violão. Na sessão de música do Jornal do Comércio de $1^{\circ}$ de março de 1837 publicou o anúncio "Na imprensa de música de Pierre Laforge na Rua da Cadeia número 89, acabam-se de imprimir as seguintes peças: método de violão segundo o sistema de Carulli e Nava, traduzido por J. Crocco" (TABORDA, 20 I 1, pp. 73).

24 S primeiros que viriam inaugurar uma série de lançamentos a princípio do século XX foram o Indicador dos acordes para violão tendo por fim adestrar em mui pouco tempo a qualquer individuo ainda sem conhecimento de música, no acompanhamento do canto e instrumentos, de Miguel José Rodrigues Vieira (1851, em Pernambuco) e o Methodo de violão - guia material - para qualquer pessoa aprender em muito pouco tempo, independente de mestre, e sem conhecimento algum de música (1876, no Rio de Janeiro). Cf.: TABORDA, 2011, cap. 3). 
Outro momento é 1916, ano em que o violão concentrou as atenções da capital pelas mãos do concertista paraguaio Agustín Barrios (1885-1944)25 em sessão reservada à imprensa, poetas, escritores e artistas, no salão nobre do edifício do Jornal do Commercio ${ }^{26}$ :

Sr. Barrios, o illustre violonista paraguayo que ouvimos hontem na audição que offereceu á imprenssa no salão do Jornal do Commercio, é um continuador da obra de Aguado, Carulli e Carcassi, não só como virtuose, também como compositor. $\bigcirc$ auditório numeroso que o appaudio, estava consciente de que tinha diante de si um artista ignorado, mas realmente notável... Em todos estes números elle foi de uma correcção impeccavel, nitido nos trechos de virtuosidade, cantante nas melodias singelas, brilhante nos accordes cheios, claro nos trinados, admirável no vibrato gemente e expressivo, preciso nos harmônicos e fiel sempre ao pensamento musical. (apud DELVIZIO, 201 1, pp. 73)

Uma figura como Barrios, que também compunha as peças que tocava e dominava um variado repertório (ANTUNES, 2008, pp. 24), foi de utilidade àquela parcela da sociedade que acreditava numa "viabilidade musical" do instrumento (algo como um ato de justiça para tirar o violão da vadiagem e levá-lo a outras "alturas"27 musicais) quanto no seu "decoro moral" (tanto pelo repertório escolhido como pela utilização de uma técnica instrumental, isto é, uma razão-mecânica de tradição europeia ${ }^{28}$ ).

25 Mencionamos o concerto de Barrios no Rio de Janeiro pela repercussão que teve, mas ele já tinha se apresentado pela primeira vez no país em 28 de agosto de 1915 , em Porto Alegre (RS) também em sessão reservada à imprensa, pois, "era de praxe que o concerto à imprensa local fosse oferecido antes das apresentações públicas, a fim de dar oportunidade para a crítica preparar os ouvintes". Cf.: DELVIZIO, 2011, pp. 48.

26 Jornal do Commercio, terça-feira, 25 de julho de 1916. Theatros e Musica - $\bigcirc$ Primeiro Violonista do Mundo.

27 Na mesma matéria de jornal, o seu autor lamenta: "Sem querer dar ao violão a hierarquia aristocrática do violino, do violoncelo e de outros instrumentos que, como ele, tiveram no alaúde o seu remoto ancestral, em todo caso acreditamos que não se faz ainda ao violão a justiça que lhe é devida - o que, até certo ponto, se explica pela dificuldade da técnica do instrumento que ninguém, quase, tenta vencer e dominar, desanimados todos pela igualdade do timbre que the dá uma feição de monotonia". (Ibid. -grifos nossos)

28 Barrios estudou a partir dos preceitos didáticos de Dionisio Aguado, Fernando Sor, Julián Arcas, e Carlos García Tolsa. Cf.: CONZÁLES, s/n, p. 14 apud EID, 20 I2, pp. 32; DELVIZIO, op. cit., pp. 27-28. 
Tudo isto, somado a um desconhecimento do repertório violonístico ${ }^{29}$, forneceu à imprensa da época o pretexto para canalizar suas críticas a uma "suposta falta de qualidade da produção violonística brasileira" (CASTACNA, ANTUNES, 1994, pp. 3), por ocasião da passagem do músico paraguaio.

No multicultural e estratificado complexo cultural chamado violão brasileiro ${ }^{30}$ de meados do século XIX e inícios dos XX, autodidatas, amadores e instrumentistas experientes não se vislumbravam solistas à altura desejada ${ }^{31}$. Era como se tudo o que incumbisse ao violão, ao "processo de formação de uma escola violonística", por assim dizê-lo, fosse popular, "quase que só definida pela maneira de tocar" (OROSCO, 200 I, pp. 20), no sentido de que carecíamos de virtuoses, literatura (repertório) e técnica instrumental (ZANON, 2006, pp. 81). Em soma: na vinda de Barrios muitos perceberam que no Brasil apenas chegávamos a uma "proto-erudição" no instrumento ${ }^{32}$.

1916 também é o ano em que o violonista Américo Jacomino (1889-1928), apelidado Canhoto ${ }^{33}$, estreia nos palcos do Teatro Municipal e do Conservatório Dramático e Musical de São Paulo, ambos lugares consagrados à cultura musical da elite paulistana da épo-

29 "Manuel Bandeira, em 1924, apesar de elogiar a sonoridade do instrumento, desconhece totalmente as composições para violão, daquele período ou de épocas anteriores". Cf.: BANDEIRA, 1924, pp. 463 apud CASTAGNA, ANTUNES, 1994, pp. 4.

30 Independente das origens culturais (ex.: nacionais ou estrangeiras) e condição de vulnerabilidade social (ex.: elite, comerciante ou empobrecido).

31 Existem exceções que as pesquisas reiteram, tais como Levino Albano da Conceição, Américo Jacomino (Canhoto), João Pernambuco e Quincas Laranjeira. Destes e outros, assim como dos critérios para a escolha dos nomes, falaremos nas páginas seguintes.

32 "Actualmente ainda temos solistas do violão de merecimento incontestável como os Srs. Brant Horta, Ernani de Figueire do e raros mais que não tivemos ainda ensejo de ouvir. $\bigcirc \mathrm{Sr}$. Barrios, porém, emerge de entre os seus collegas com um relevo frisante, porque consegue do violão o máximo de effeitos da mais variada espécie; Elle levantou o violão a uma hierarquia superior. Tocado pelo Sr. Barrios, não conhecemos, com exepção do piano ou dos instrumentos de teclado, nenhum instrumento que, como o violão, se preste ao canto e ao acompanhamento simultâneos, com a riqueza de recursos que tem esse instrumento, aristocratizado por Carulli e Aguado, e com uma surpreendente formação de accordes, que se succedem indefinidamente, encadeados pelas modulações do mais extranho sabor." (sic.), Jornal do Commercio, quinta-Feira, 10 de agosto de 1916. Theatro e Musica Concertos - Recital - Barrios. -grifo nosso). $\bigcirc$ mesmo sentimento de que ainda o país não tinha violonistas concertistas permanecerá vigente por vários anos. Cf.: POMBO, 1929, s.p. apud TABORDA, 2011, pp. 100.

33 Pois aprendeu a tocar sem inverter a posição das cordas, isto é, as três primeiras cordas do violão - as agudas - com o polegar da mão esquerda, e as graves - os baixos - com o dedo anular, médio e indicador. (TAUBKIN, 2004, p.35 apud ESTEPHAN, 2007, pp. 40)

\section{8}


ca. Chamado de "Rei do violão brasileiro"34,"o aplaudido violonista da Casa Édison" (CASTACNA, ANTUNES, 1994, pp. 6), Jacomino está entre os primeiros a sintetizar o gosto da população da época pelo violão seresteiro, em particular a valsa (BARTOLONI, 2000, pp. 112). Embora autodidata, Canhoto guardava afinidades com o violão "tarreguiano" no sentido em que este "não tinha um perfil muito diferente do repertório praticado aqui (pequenas peças românticas, música de salão e transcrições)" (CLOEDEN, PEREIRA, 2012 , pp. 79).

A seguir, no ano de 1917, destaca-se a passagem de Josefina Robledo (1892-1972), "que possuía a credencial de ter sido aluna de Francisco Tárrega (1852-1909), grande nome da música espanhola, que viria a estabelecer os fundamentos da escola moderna" (TABORDA, 2011, cap. 2):

\begin{abstract}
"Realisa-se esta noite, no Conservatorio Dramatico, o annunciado concerto desta notavel artista, com a cooperação do distincto violinista sr. Fernando molina. Vae o nosso publico travar conhecimento com uma senhora em cujas mãos o violão attinge a mesma hierarchia da harpa, do piano e do violoncello, dizendo pelas suas cordas a musica dos grandes mestres e produzindo uma suavidade de sons que deleita os assistentes. A sra. Robledo é, com effeito, um temperamento impressionavel, que allia á delicadeza da execução um sentido de interpretação desenvolvidissimo". (
\end{abstract}

Voltando um pouco atrás, na noção de instrumento-documento, temos que a então capital do país recebeu entre 1916 e 1917 duas presenças estrangeiras muito peculiares, mas que causaram o mesmo impacto: o de revelar as possibilidades performáticas do violão e, consequentemente, confirmar a sua viabilidade social (se o pensarmos enquanto projeto ideológico de um "violão-arte").

Por um lado, Barrios representava o legado do violonista autodidata, "que acrisolou sua refinada técnica e seu latino-americano gosto

34 Faleceu o maior violonista Brasileiro: Canhoto foi o vencedor do concurso "O que é nosso". Folha da Manhã, São Paulo, 08 set. 1928, apud BARTOLONI, 2000, pp. 113.

35 "Josefina Robledo". O Estado de São Paulo. col. Artes e Artistas, domingo 29 de julho de 1917, pp. 4. 
no consistente e conservador ambiente violonístico da Bacia do Prata, tocando em um violão com cordas de aço" (CLOEDEN, PEREIRA, 2012, pp. 81-82) enquanto seu par de nacionalidade espanhola "era literalmente uma dama do violão moderno ${ }^{36}$ da época" (Ibid.). Ambos viveram alguns anos no país ${ }^{37}$, tendo maior repercussão as suas apresentações no Rio de Janeiro e São Paulo.

Deixando de lado certas interpretações subjetivas da imprensa da época, com sua linguagem quase literária ${ }^{38}$, fica a pergunta sobre qual teria sido o impacto da presença de ambos os violonistas na grande "comunidade" de anônimos autodidatas, amadores e instrumentistas experientes.

No caso de Barrios, estamos frente a um instrumento-documento bastante complexo: é um violão muitas vezes elogiado pela versatilidade (EID, 2012, pp. 52-60) e outras tantas criticado pela rudimentariedade (DELVIZIO, op. cit., pp. 180)39; é uma opção político-poética que encarnou o alter-ego "Mangoré"40; é um paraguaio que viveu grandes decepções em sua terra natal ${ }^{41}$ e teve muita vontade em desbravar 0 Brasil|42.

Em contraste à efusividade guarani, o instrumento-documento de Robledo, que se conta entre os mais sobressalientes discípulos do lendário Tárrega (PRAT, 1934, pp. 264), trouxe o refinamento europeu das cordas de tripa ${ }^{43}$ e, evidentemente, uma leitura feminina daquele instrumento tão desmoralizado pelo preconceito aos seresteiros:

36 Moderno enquanto os ensinamentos de Tárrega foram assim considerados na passagem do séc. XIX e boa parte das primeiras décadas do XX. Cf.: TANENBAUM, 2003, pp. 183- 184.

37 Para Robledo, entre 1917-1923, cf.: PRAT, 1934, pp. 263-264. Para Barrios, entre 19151920 a primeira vez, e entre 1929- 1931 a segunda vinda. cf.: DELVIZZIO, 201 I, pp. 46- 153.

38 Cf.: SODRÉ, Nelson Werneck. A grande imprensa. In História da imprensa no Brasil. 4ed. Rio de Janeiro: Mauad, 1999, pp. 251-390

39 Pelas críticas ao uso de cordas de aço.

40 Cf.: Ibidem, pp. 185-191.

41 Cf.: Ibid., pp. 155, 184.

42 Com "cerca de 187 performances [entre elas saraus, concertos, participações em cinemas, rádios e etc.] em 36 cidades de 14 estados brasileiros durante suas duas turnês" (Ibid., pp. 174)

43 Pois, "as cordas de aço - muito comuns no Brasil, por sua maior durabilidade, resistência e fácil acesso - eram impensáveis dentro da estética tarreguiana e segoviana" (CLOEDEN, PEREIRA, 2012, pp. 80)

\section{0}


Assim, o fato de Robledo aparecer no Brasil tocando um instrumento que fazia parte do imaginário masculino, sempre vinculado à prática de boêmios e seresteiros, vai contrabalançar estas duas realidades tão distintas: a delicadeza feminina com a má fama e desprezo pelo violão. Sua imagem feminina contribui para melhor aceitação do instrumento pela elite, colaborando para sua inclusão nas salas de concerto. (PORTO, NOCUEIRA, 2007, pp. 7).

Até aqui, estas datas (1908, 1916 e 1917) e nomes (Catulo de Paixão Cearense, Agustín Barrios, Américo Jacomino e Josefina Robledo, respectivamente) podem ser de utilidade para confrontá-las com outras questões que atravessaram a vida musical do eixo Rio-São Paulo e foram fundamentais para definir as identidades do violão brasileiro e suas leituras (morais, políticas e poéticas) na sociedade: a instalação da indústria fonográfica, o circuito comercial das artes (lugares e formatos de apresentação, interação de linguagens etc.) e o conceito de popular e erudito na passagem do século.

\section{O violão brasileiro sempre foi uma arte}

O violão na virada do século é permeado por diversos eventos próprios da vida moderna que expandiram as atividades poéticas e musicais, "fosse no mercado editorial, no mercado mais amplo de diversões que incluía os circos, teatros e festas da capital federal, fosse, ainda, no incipiente mercado fonográfico" (FERLIM, 201 1, pp. 190).

Entre a nascente produção de discos e a chegada do rádio, nas primeiras décadas do século XX, surge uma relação de poder ímpar na socialização da música: aparece a figura do ouvinte consumidor (BARTOLONI, 2000, pp. 64-67), principalmente nas emissões radiais que submetem o país a um repertório popular massivo (e urbano, pois o epicentro radial é metropolitano), concomitante ao legado oscilante entre o erudito e o popular (tradicional e/ou folclórico). Nessas primeiras décadas, Américo Jacomino ("Canhoto") já iniciava sua carreira profissional e sua escalada discográfica (ANTUNES, 2002, pp. 53-55). E o motor do progresso econômico que iria capitalizar a moral do violão-povo numa estratégia de mercado com evidentes implicações sociais:

\section{1}

REV. TULHA, RIBEIRÃO PRETO, v. 2, n. 2, p. 227-250, jul.-dez. 2016 
"Foi por meio deles [os violonistas] que nossas fábricas de discos se puseram em contato com o povo. É assim que a Columbia Gramophone Company já tem em São Paulo funcionários encarregados de montar naquela capital um grande Studio, pretendendo fazer o mesmo aqui". (Violão em Discos, 1928, pp. 20 apud Bartoloni, op. cit, pp. 65 grifo nosso).

Porém, analisando o cenário da Primeira República (1889-1930) boa parte da historiografia do violão (conforme elencado no subtítulo anterior) persiste no discurso de uma cultura violonística nacional resgatada graças a uma erudição de concerto, que introduz seus métodos, sua literatura, seu repertório e seus expoentes. Esta continuidade não chamaria a atenção se fosse apenas o relato, por exemplo, da implantação da tradição violonística europeia no Brasil. Em seu lugar, acaba registrando, nos códigos de uma cultura de tradição escrita, o apontamento de um cânone e, quiçá o mais importante, a aplicação de uma metodologia etnocêntrica e positivista para compreender os percursos do instrumento em nosso país, face aos avanços da modernidade:

\begin{abstract}
[...] para o historiador da arte, o cânone pode ser uma armadilha. Orientar-se unicamente por ele significa renunciar à pesquisa original de fontes e reproduzir ingenuamente os discursos tradicionais. A ideia dos grandes autores e obras, bem de acordo com o paradigma historiográfico herdado do século XIX, foi fundamental para a construção do discurso predominante na história da música ocidental e, via de regra, foi reiterada pelos estudiosos da música popular ${ }^{44}$ até recentemente. (BAIA, 2012, pp. 72).
\end{abstract}

Estas considerações foram apontadas, principalmente, a partir de trabalhos na área da História, preocupados com o escasso relativismo (e consequente reiteração de dados sem maiores questionamentos) na produção bibliográfica da história da música, em particular as pesquisas musicológicas que estabelecem uma distinção entre "o fazer ciência e o fazer arte" (MORAES, 2000, pp. 209). Se trata de um corpus, um discurso ordenador produzido a partir de três aspectos: a biografia do

44 Paradigma historiográfico que também está presente na construção do discurso predominante na história da música erudita ou de concerto. 
grande artista, o centralismo na obra de arte, e a autonomia dos estilos, gêneros ou escolas artísticas (ld., pp. 206).

primeiro aspecto celebra a epifania do gênio musical, seu caráter de artífice, sua essência, sua índole geradora de transformações e mudanças no campo das artes; o segundo aspecto deriva numa construção ontológica da forma, estrutura e linguagem, enquanto que a autonomia dos estilos é a transposição da mesma visão ontológica desta vez aplicada aos gêneros. Note-se em todos estes aspectos o distanciamento de outros contextos (político, social, econômico, cultural) que reforçam uma compreensão fenomenológica dos eventos $e$, porque não, sua condição de narrativas totalizadoras.

Eis que penso: o violão foi um instrumento que sofria de preconceito na sociedade como um todo? Para identificar melhor os atores da sociedade, caberia perguntar quem considera o violão um instrumento desmoralizado e associado à vadiagem? Possivelmente a imprensa e a elite política e econômica da época, junto a seus representantes institucionais (acadêmicos, escritores, músicos, juristas etc.). Que porcentagem da população representam todos eles em relação aos "desmoralizados violonistas"? Possivelmente menos do 10\% da população. Então, podemos afirmar que na passagem entre o século XIX e XX o Brasil já possuía um complexo cultural chamado violão brasileiro que, embora amaldiçoado por uma minoria poderosa, era desde sempre emblemático e prolífico para uma grande maioria de anônimos autodidatas, amadores e instrumentistas experientes. Por isso, quando as pesquisas musicológicas se referem ao estigma do violão no Brasil das primeiras décadas do século XX, o fazem repercutindo o discurso daquela minoria, fazendo da vergonha de poucos " $A$ " vergonha nacional.

E será que esta vergonha é correlata de um discurso maior? Abreu e Gomes (2009) chamam a atenção para uma periodização da história republicana do Brasil imaginada e adotada pelos ideólogos autoritários das décadas de 1920/30 (e muito vigente até nossos dias), que acusam a Primeira República de liberal, oligárquica, fraca, inepta, europeizante e política e culturalmente afastada do "povo brasileiro'." (Id., pp. 3). Se trataria de uma narrativa inventada que deliberadamente não destaca ou ignora outras dinâmicas sociais, políticas e culturais.

\section{3}


Quer dizer, marginaliza-se, nunca ingenuamente, todo um conjunto de vivencias, envolvendo diferenciados grupos sociais, que demandavam políticas às autoridades públicas, propondo e implementando uma série de iniciativas através de suas formas de associativismo, fossem elas na área da educação, da saúde, da política econômica, da regulamentação do mercado de trabalho e da expressão cultural, entre outras. Um processo de escolhas do que lembrar e do que esquecer que é obra política articulada desde os anos 1920, mas que permanece tendo vigência na historiografia e no ensino de história sobre a Primeira República. (ld., pp. 4).

Fazendo uma relação com o capítulo anterior, caberia inferir a existência de um discurso de construção da brasilidade violonística marcado pela culpa de não ter desenvolvido uma relação aristocrática com o instrumento, como também de sermos "essencialmente" bárbaros ao não procuramos "naturalmente" a sua sofisticação técnica? Esse discurso também carregaria, implicitamente, a exclusão de outras metodologias e experiências didáticas que não resultem num virtuosismo de concerto. Portanto, a tradição escrita (literatura do violão erudito) simbolizaria o que há de mais desenvolvido (em termos evolucionistas, progressistas e positivistas), deixando para o folclore nacional o papel de saberes de tradição oral, e para o popular-massivo o papel de saberes de tradição fonográfica. Mas, a história nos demonstra de que o Brasil não era só isso:

Se intelectuais e governantes na Primeira república de fato defenderam e incrementaram políticas excludentes, autoritárias e dentro de um gosto tido como europeu, as avaliações sobre o período não podem se restringir a isso. Músicos [do] Instituto Nacional de Música, antes da Semana de arte Moderna de 1922, investiram na construção de uma música que identificavam como brasileira. No início do século XX intelectuais republicanos já tinham conferido ao que definiam como música popular, o folclore ou o samba urbano, os atributos da mestiçagem e da brasilidade. Por outro lado, "músicas populares", como lundus, maxixes e choros, afirmaram-se como gêneros e negócios lucrativos, no mercado editorial e de diversões, exatamente entre o final do século XIX e início do XX. Não precisaram das décadas de 1920 e 1930 para serem identificadas como coisas nacionais. (ABREU, 201 l, p.73).

\section{4}

REV. TULHA, RIBEIRÃO PRETO, v. 2, n. 2, p. 227-250, jul.-dez. 2016 
Homologamente poder-se-ia pensar o violão brasileiro e suas apropriações "nativas" que tanto nasceram do conhecimento empírico do instrumento como da circularidade entre as elites e a música popular (VIANNA, 2002, pp. 37-54), razão pela qual somos convidados a relativizar: até que ponto há certeza de que 1916 é mesmo o ano que o violão brasileiro se torna arte? (CASTACNA, ANTUNES, 1994). Em que tipo de violão se pensa esta afirmação? Em que contextos estão ancorados o grau de relevância dos eventos musicais desse ano (os concertos de Josefina Robledo, Agustín Barrios e Canhoto)? Se definitivamente "os exemplos de intelectuais e políticos racistas e europeizantes não podem servir para resumir a história cultural e política da Primeira República" (ABREU, COMES, 2009, pp. 13) o que pode ser feito para trabalhar esta lacuna historiográfica do violão brasileiro, que diz respeito apenas das "histórias de vencedores" do violão de concerto? Como fica a paisagem violonística de anônimos autodidatas, amadores e instrumentistas experientes e suas "histórias de vencidos"? Também é necessário questionar como ficam as relações de poder entre a brasilidade de - por exemplo - um violonista de valsas que toca "por música" (lendo partitura) e um violonista que toca "sem música"45:

Devemos também promover a crítica do temperamento igual, que elimina as riquezas melódicas de culturas não ocidentais. É preciso que se questione a escrita como meio de controle e desfazer o divórcio romântico-modernista entre o escrito e o oral em música. Uma música de tradição oral pode se transformar através da escrita e conhecer uma segunda vida dentro de um outro contexto cultural. (CÂMARA DE CASTRO, 2013, pp. 50).

Na prática, ambas as "frentes de linguagem" (o popular e o erudito) estiveram misturadas, seja na performance ou na técnica composicional. A diferença entrou em ação na hora de abrir os portões da Academia: não se reconheceu nem se enxergou alguma erudição oral no autodidata, no legado simbólico do amador, do profissional experiente, base de uma identidade do violão brasileiro que já existia na radiografia da cidade. Bastava perguntar, como parafraseando uma charge de Paderneiras, "dize-me o que tocas... direi de que bairro és".

45 Que na fala coloquial é o músico que toca "de ouvido".

\section{5}


Dize-me o que cantas.... direi déque bairro és

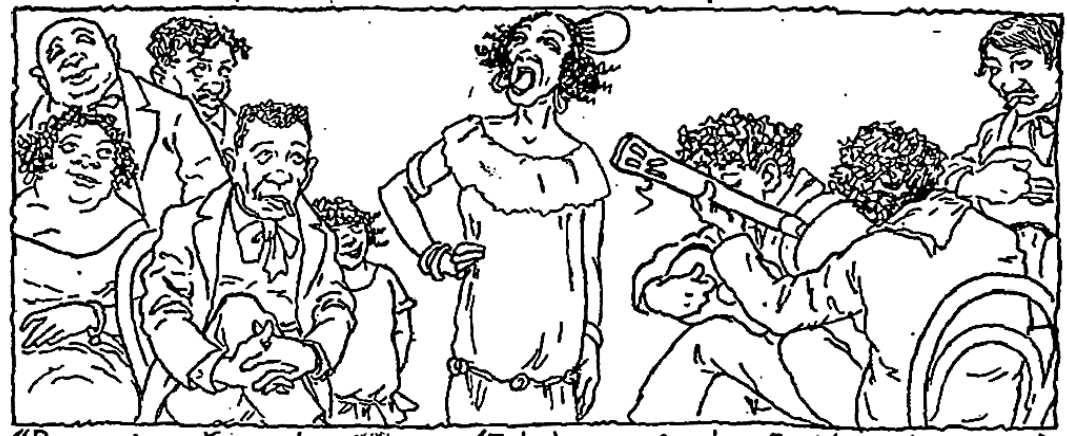

"Bem sei que tu me desprésas... (Cidade nova, Gambáa, Saude e adjacencias)

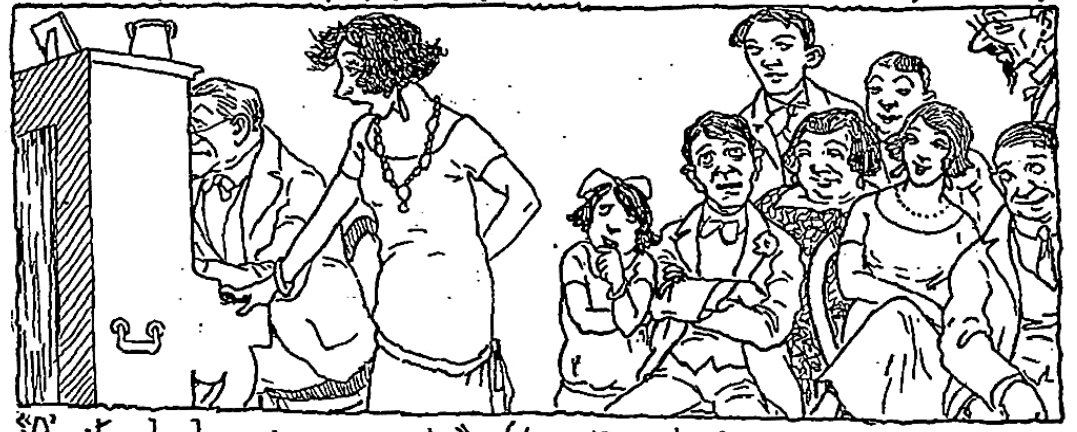

"A'noite o plenilunio é como um sonho". (S.Christovam.Villa Tsabel, e visinhancas).

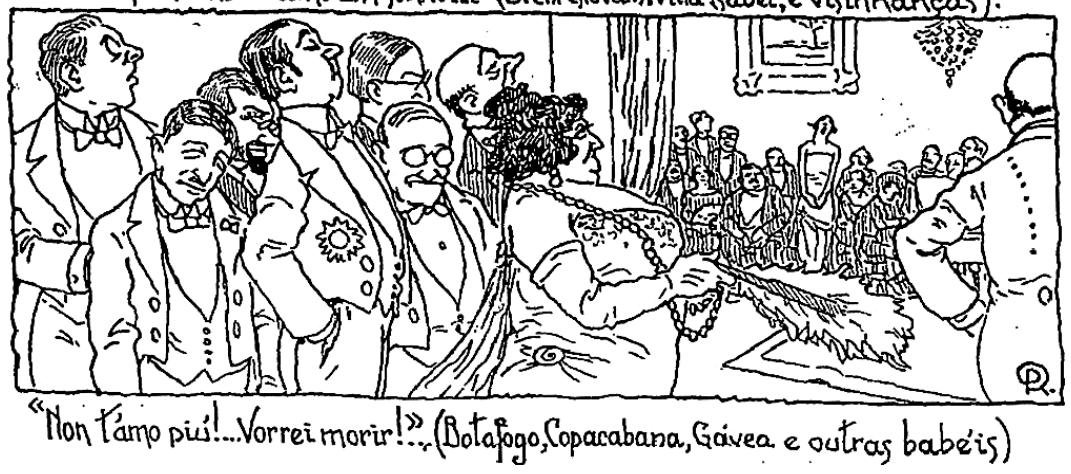

Fig.2. Desenhos de Raúl Paderneiras, em Cenas da Vida Carioca, de 1924. (NERY, 2000, pp. 156). Em que bairros o violão brasileiro sempre foi uma arte? 


\section{Referências}

ABREU, Martha. "Histórias musicais da Primeira República". ArtCultura, Uberlândia: v. 13, n. 22, p. 71-83, jan.-jun. 2011.

ANTUNES, Gilson. "Américo Jacomino "Canhoto" e o início do violão solo em São Paulo". In ANAIS DO II SIMPÓSIO ACADÊMICO DE VIOLÃO DA EMBAP. Curitiba: EMBAP, 2008.

AUCUSTO, Antônio. A questão Cavalier: música e sociedade no Império e na República - 1816-1914. 2008, 28 If, Tese (Doutorado em História Social) Rio de Janeiro: UFRJ: PPCHIS.

BAIA, Silvano Fernandes. A música popular na historiografa: reflexões sobre fontes e métodos. ArtCultura, Uberlândia: v. 14, n. 24, p. 61 80 , jan.-jun. 2012.

BARTOLONI, Giacomo. Violão: a imagem que faz escola. São Paulo 1900-1960. 2000. 31 f. Tese (Doutorado em História) - Faculdade de Ciências e Letras de Assis, Universidade Estadual Paulista, Assis.

CÂMARA DE CASTRO, Marcos. "Educação: o campo maior da pesquisa em música". In ANAIS DO SIMPÓSIO DE ESTÉTICA E FILOSOFIA DA MÚSICA, SEFIM/UFRGS. Porto Alegre: v. 1, n. 1. 2013, pp. 44-53.

CASTACNA Paulo; ANTUNES, Gilson. "1916: o violão brasileiro já é uma arte". Cultura Vozes, São Paulo: ano 88, n. 1, p.37-51, jan./fev. 1994.

CASTACNA, Paulo; SCHUARZ, Werner. "Uma Bibliografia do Violão Brasileiro (1916-1990)". Revista Música, vA, n.2. São Paulo: 1993, pp. 190-218.

DELVIZIO, Cyro Mauricio. Agustín Barrios e o Brasil: um relato histórico sobre sua interação com o meio artístico brasileiro. Rio de Janeiro, 2011. Dissertação (Mestrado em Musicologia) - Escola de Música, Universidade Federal do Rio de Janeiro, Rio de Janeiro. 
EDMUNDO, Luiz. O Rio de Janeiro do meu tempo. Brasília: Senado Federal, Conselho Editorial, 2003.

EID, Félix C. Música e Identidade na América Latina: $\bigcirc$ caso de Agustín Barrios "Mangoré". 2012. Dissertação (Mestrado em Música). Instituto de Artes, Universidade Estadual Paulista (UNESP), São Paulo.

ESTEPHAN, Sérgio. Viola minha viola. A obra violonística de Américo Jacomino, o Canhoto (1889-1928), na cidade de São Paulo: 2007. 257f. Tese (Doutorado em História). Pontificia Universidade Católica de São Paulo. São Paulo: PUC-SP.

FERLIM, U. D. C. "Catulo da Paixão Cearense e os embates cancioneiros". In O longo século XIX. Revista Brasileira de Música. Rio de Janeiro: v. 24, n. 1, jan.jun. 201 1, pp. 17 1- 192.

CLOEDEN, Edelton; PEREIRA, Marcelo F. "De maldito a erudito: caminhos do violão solista no Brasil". In Composição, Revista de Ciências Sociais, $\mathrm{n}^{\circ}$ 10, ano 6. Campo Grande: UFMS, 2012, pp. 68-91.

COMES, Ângela de Castro; ABREU, Martha. "A nova 'Velha' República: um pouco de história e historiografia". Tempo, Niterói: Ed. da UFF, v. $13, n^{\circ} 26$, jan. 2009.

HODDER, lan. The interpretation of documents and material culture. In: DENZIN, Norman K; LINCOLN, Yvonna S. Collecting and interpreting qualitative materials. Handbook of qualitative research paperback edition, vol. 3. Thousand Oaks: Sage Publications, 1998, pp. 1 10-129.

MORAES, J. G. V. “História e música: canção popular e conhecimento histórico". Rev. Brasileira de História, v. 20, n³9, 2000, pp. 203-221.

NERY, Laura Moutinho. Cenas da Vida Carioca, Raúl Pederneiras e a belle époque do Rio de Janeiro. 2000. 269f. Dissertação (Mestrado em História Social). Pontificia Universidade Católica do Rio de Janeiro: Programa de Pós Graduação em História Social da Cultura. Rio de Janeiro. 
OLIVEN, Ruben Ceorge. "Cultura Brasileira e identidade nacional (o eterno retorno)". In O que ler na ciência social brasileira: 1970-2002. Brasília: Editora Sumaré, 2002, pp. 15-43.

OROSCO, Maurício Tadeu dos Santos. O compositor Isaias Savio e sua obra para violão. 200 I. Dissertação (Mestrado em Música). Programa de Pós Graduação em Música, Escola de Comunicações e Artes, Universidade de São Paulo, São Paulo.

PORTO, Patrícia Pereira; NOCUEIRA, Isabel Porto. Imagem e representação em mulheres violonistas: algumas reflexões sobre Josefina Robledo. In: Anais do XVII Congresso da ANPPOM. Universidade Estadual Paulista (UNESP), Instituto de Artes, Departamento de Música. São Paulo: 2007. Disponivel em <http://antigo.anppom.com.br/anais/anaiscongresso_anppom_2007/musicologia/musicol_PPPorto_IPNogueira.pdf $>$ (acessado em 22/11/2015).

"Robledo". In PRAT, Domingo. Diccionario biográfico, bibliográfico, histórico, crítico de guitarras (instrumentos afines), guitarristas (profesores, compositores, concertistas, lahudistas, amateurs), guitarreros (luthiers), danzas y cantos, terminología. Buenos Aires: Romero y Fernández, 1934. pp. 263-264.

RODRICUES, Antonio Edmilson M. Nair de Teffé: vidas cruzadas. Rio de Janeiro: Editora FCV, 2002.

TABORDA, Marcia. Violão e identidade nacional: Rio de Janeiro 1830- 1930. Rio de Janeiro: Civilização Brasileira, 2011.

VIANNA, Hermano. O mistério do samba. 4ed. Rio de Janeiro: Jorge Zahar Ed.; Ed. UFRJ, 2002.

ZANON, Fábio. "O violão no Brasil depois de Villa-Lobos". Violão com Fábio Zanon, v. 1, 2006. 


\section{Sobre o autor}

Violonista e Etnomusicólogo. Doutorando em Música (PPCMUS-ECA/USP) e Mestre em Música (IA/UNESP). Professor de Violão Popular na Fundação da Artes de São Caetano do Sul. Autodidata, prosseguiu seus estudos de especialização no instrumento com Celso Delneri e Paulo Porto Alegre (EMM). Já compôs peças para violão baseadas nos ritmos da costa peruana e na música popular brasileira. Temas do seu interesse: violão latino-americano, etnomusicologia do violão, repertório crossover para violão erudito e popular, ensino do violão popular.

Recebido em 12/09/2016

Aprovado em 16/12/2016 